\title{
Poesia e morte: JoÃo Cabral de Melo Neto
}

\author{
Maiara Knihs \\ Mestranda em Teoria Literária PPGL/UFSC/CAPES \\ maiaraknihs@yahoo.com.br
}

\begin{abstract}
PARALISIA CABRALINA - Súbito enrijecimento do nervo poético, causado por leituras intensivas da obra de João Cabral de Melo Neto. O cabra da peste acometido desse mal começa a ver tudo em quadradinhos e a só reconhecer rimas toantes. Nos casos mais graves, desenvolve pedra nos rins, na bexiga e na veia. Apresenta tendências para a litogravura, a marmoraria, ou coleciona cristais. Tem coração de pedra, e só se comove com agrestes, caatingas e canaviais pernambucanos. Normalmente, leva uma vida e morte severina.
\end{abstract}

Paulo Leminski, em Os perigos da literatura

A obsessão formal aliada à obsessão de certas imagens, ou, como prefere o próprio poeta, de algumas ideias fixas ${ }^{1}$, são uma marca da obra cabralina. Marca da obsessão na e pela escritura. Incluindo, ainda que de maneira menos acentuada, os primeiros livros em que experimenta, muito via digestão da poesia de Murilo Mendes e de Carlos Drummond de Andrade, certo surrealismo - como é o caso do livro Pedra do sono e do poema dramático Os três mal amados - passando pelo auge do seu construtivismo - no caso de $O$ engenheiro e de Psicologia da composição - a poesia do poeta pernambucano trabalha essa obsessão colocando em jogo pelo menos dois grandes fantasmas: o nordeste brasileiro e o sul espanhol. Essas imagens se desdobram em outras imagens - a pedra, a seca, a plantação de cana, os cemitérios do nordeste e, ao mesmo tempo, correspondem à dança flamenca, ao canto à palo-seco, à tauromaquia sevilhanas.

O objetivo deste texto é trabalhar algumas dessas imagens que ferem, que apontam para o desalento da vida, seja apelando à seca do sertão nordestino ou à tauromaquia de Sevilha. Interessa aqui mais especificamente perceber como essa poesia, agenciando imagens que aludem sempre à morte, que falam da vida a partir da morte, funciona como um sintoma que caracteriza a literatura e também a própria vida: uma exposição da falta.

No poema-livro O cão sem plumas, o rio Capibaribe, numa de suas primeiras aparições como personagem central, apresenta-se como uma das máscaras que o nordeste cabralino veste. Esse rio, nascido no interior do Pernambuco, corta o estado, chega a Recife e desemboca no Atlântico; esse rio leva a passear pela vida (miserável), e, como uma lâmina, fere. Desse corte surge o cão sem plumas, uma imagem atribuída tanto ao rio quanto aos homens ribeirinhos:

${ }^{1}$ Referência ao nome do livro publicado em 1955 Uma faca só lâmina ou serventia das ideias fixas. 


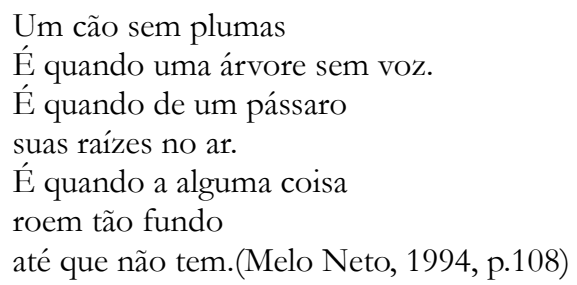

Entre outros lugares nos quais seria possível verificar a irrupção da morte na poesia cabralina, O cão sem plumas serve aqui como um marco que será reiterado no decorrer de toda a poesia subsequente. Afinal, cortante, esse rio ganha a voz no livro posterior, O rio, e testemunha sua descida ao encontro do mar. Além do rio que flui "como uma espada de líquido espesso", 2 o rio encontra outra lâmina, a folha da cana, matéria de sobrevivência do homem que alimenta as usinas que se alimentam dos homens. Nesses poemas, o Capibaribe deixa-se ser e ativamente é uma testemunha da morte. Diz o rio:

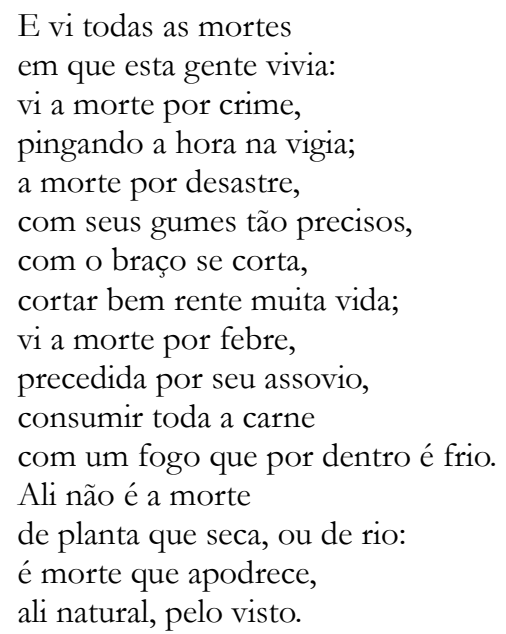

(Melo Neto, 1994, p.132-133)

O rio que conta sobre a morte, que leva a morte e a vida, que, portanto, flui com um cortejo de vida e de morte, é ainda o guia, muitas vezes intermitente, de outra vida, a vida de Severino. Ali na jornada do retirante, a vida confundida com a morte se torna então questão saliente num livro que se pretende a celebração do nascimento do menino Jesus, Morte e vida severina: auto de natal pernambucano. O retirante Severino tem sua vida sempre por um fio, ou, como um fio, tecido por galos ou pelas parcas, está sempre a ponto de se romper. É pelo mesmo fio que está a vida do toureiro. Valeria apontar que entre os poemas O rio (1953) e Morte e vida severina (1954-1955) aparecem as primeiras correspondências das imagens nordestinas com a imagens sevilhanas; isso ocorre no livro Paisagens com figuras (1954-1955). Junto aos cemitérios pernambucanos e seus fantasmas, surge, por exemplo, o

${ }^{2}$ Verso de O cão sem plumas, parte II (Paisagem do Capibaribe). 
poema "Alguns toureiros", um elogio a Manolete, “[...] o que melhor calculava/ o fluido aceiro da vida,/o que com mais precisão/ roçava a morte em sua fímbria [...]”. (Melo Neto, 1994, p.158)

Manuel Laureano Rodríguez Sánchez, o Manolete, conhecido como um dos mais precisos toreros, foi morto pelo touro Islero, na Plaza de Toros de Linares, no ano de 1947. João Cabral reuniu uma grande quantidade de material sobre Manolete e nutria uma grande admiração pelo toureiro cordobês. Em uma das reportagens guardadas por João Cabral, fotos do embate seguiam com a seguinte legenda: "El último embate de 'Manolete' con el toro que se llevó por delante la vida... Es el instante en que se dispone a cuadrar a 'Islero' para estoquearle. De la suerte saldrian toro y torero heridos de muerte" ${ }^{3}$. O vocábulo tragédia é inúmeras vezes evocado pelos jornais que foram conservados por João Cabral por mais de cinco décadas e, certamente, não aparece ao acaso. A tragédia que se arma com a morte do torero, no entanto, não é menos trágica do que aquela em que só o touro morre. Toda a dimensão trágica da tauromaquia entra em jogo. A morte de Manolete não veio à baila diretamente no poema "Alguns toureiros", de João Cabral, porque ali o que lhe interessava era o embate trágico em si, a convivência entre o dionisíaco e o apolíneo, para usar os termos de Nietzsche, o drama tauromático, a composição poética.

Michel Leiris, ao pensar a tauromaquia, não se abstém de apontar para o trágico. O que o desempenho do torero tem de singular, nesse espetáculo, segundo Leiris, é justamente seu lado essencialmente trágico: "todas as ações executadas são preparativos técnicos ou cerimoniais para a morte pública do herói, que não é outro senão esse semideus bestial, o touro". (Leiris, 2001, p.18) O autor de Espelho da tauromaquia vai além e afina essa ideia com a ideia de arte:

$\mathrm{Na}$ medida em que se pode dizer que, ao menos simbolicamente, qualquer atividade estética legítima traz consigo, refletida ou não na obra, sua porção trágica (obrigação para o verdadeiro artista, de ser autêntico, de participar inteiro daquilo que criou, a par da ideia de que para ele há a necessidade vital de ir até o fim, sem que intervenha qualquer trapaça - como o matador que dá o golpe no lugar certo, estocando até o fim e projetando-se entre os chifres) [...] (Leiris, 2001, p.19)

De fato, a tauromaquia de modo geral atravessou o poeta e surgiu como um fantasma na sua obra. Tal qual a imagem do esgrimista baudelairiano, como Walter Benjamin lembra no seu estudo sobre o poeta francês ${ }^{4}$, o trabalho literário exige um esforço físico

\footnotetext{
${ }^{3}$ Reproduções fac-similares deste material estão reunidas no livro que compila a correspondência de Cabral com Manuel Bandeira e Carlos Drummond de Andrade, organizado por Flora Süssekind.

${ }^{4}$ Referência ao ensaio "Sobre alguns temas em Baudelaire" inserido no livro Um lírico no auge do capitalismo.
} 
(corpóreo) e preciso. No entanto, nas correspondências cabralinas, diferentemente das correspondências do poeta em Baudelaire, o sacrifício está implícito - a morte. Esse esforço de vida tão poeticamente observado pelo poeta equivale ao esforço de vida do nordestino. O toureiro, o poeta, o retirante vivem numa luta constante com a vida/morte, vivem, como diz o poema "Diálogo", "no fio agudo das facas/ o fio frágil da vida". Essa é a vida severina. Essa é uma vida que não se desvincula da morte.

A vida dessa poesia poderia mesmo ser pensada como experiência da morte. Nesse sentido, vale lembrar que a vida enquanto antecipação da possibilidade de morte foi com Heidegger chamada de dasein, o ser-aí, ou o aí do ser na linguagem, questão retomada por Agamben no livro $A$ linguagem e a morte. Nesse livro, o filósofo italiano se propõe a pensar o lugar da negatividade a partir do pensamento de Hegel e Heidegger. Agamben vai chamar a atenção para o elemento constituidor do dasein. $\mathrm{O}$ estudo da negatividade traz à tona o problema da linguagem que, na vertente hegeliana, enquanto mediadora, conserva o indizível, dizendo-o. Concordando com certos aspectos hegelianos e somando-os às ideias de Heidegger, Agamben reitera que a linguagem é o querer dizer, pois aquilo que se quer dizer é impossível. Nessa fratura entre o dito e o indizível pensada pela tradição filosófica por muitos vieses, é que a poesia de João Cabral de Melo Neto se insere. Nessa fissura, o que reina é a morte. Análoga à experiência da infância, esse é um lugar de passagem, onde a linguagem pode se converter em discurso. Assim como nos shifters, o significante pode significar. Dessa passagem, seria possível dizer que, da língua à fala, a voz se torna saliente.

Agamben, no livro em questão, foca na dimensão negativa da Voz enquanto aquilo que não é mais mero som e também não é ainda um significado. Pensando nessa Voz que silencia os sentidos, que coloca o corpo em evidência, o poema "Lembrando Manolete" é a escuta desse som que, ao se colocar entre o som puro e a linguagem, reverbera o silêncio do sentido:

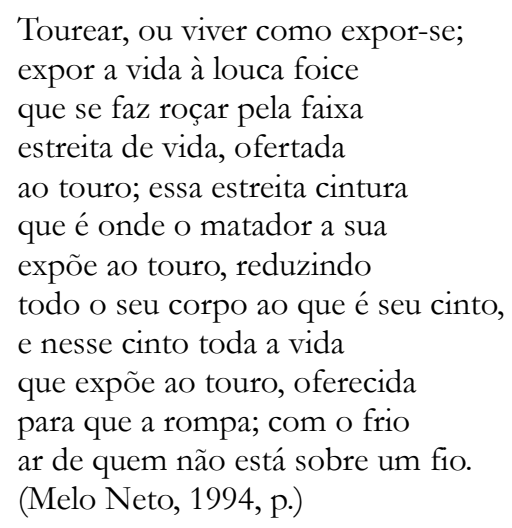

Neste poema que traz tão enfaticamente a questão da vOz no uso recorrente do 
enjambement, portanto do som e do tempo, do ritmo, do corte (sintático), ou seja, do mais que o som e o ainda não sentido, há um eco de Manolete. Aqui Manolete já aparece como um duplo fantasma, afinal, é lembrança - a imagem da memória da imagem de Manolete. Aludindo uma vez mais a Leiris, seria possível trazer para este jogo de leitura a ideia de que a tauromaquia é um exemplo típico de arte na qual a condição essencial da beleza está "num descompasso, num desvio, numa dissonância", uma referência aqui ao movimento de desvio do torero, que deixa o espaço vazio para o touro imediatamente ocupá-lo, evitando por um triz que o golpe o acerte. O movimento ritmado do torero ou do poeta é um movimento preciso e arriscado, é uma questão de vida e de morte. E cabe dizer que implícita nessa questão, que é, antes de mais nada, do ser, está também a questão do tempo.

É pelo viés do som que gostaria de pensar a questão do ser e também do tempo na poesia cabralina. Para pensar o ser, Giorgio Agamben enfoca a voz enquanto o shifter supremo - a máxima negatividade -, porque é o puro querer dizer, como mencionado anteriormente, o mais que o som e o ainda não sentido. Jean-Luc Nancy para pensar o mesmo problema, no entanto, pelo viés da posição política, volta-se para o estar à escuta. A brincadeira que o filósofo francês faz com as palavras homófonas "entender" e "escutar" na língua francesa é também um chamado para o ouvir estético e não meramente para a compreensão do sentido. Diz Nancy, com muita afinidade com as concepções agambenianas, que, em relação ao dizer, isto é, a todo discurso, há sempre um entender, mas também há uma escuta. Nessa escuta se faz necessário que o sentido não se conforme somente com o ter sentido, mas, sim, que ressoe.

Ressoar ou deixar ressoar o som ${ }^{5}$ é estar à escuta do som e do sentido, ali onde eles se mesclam, ali onde ressoam um no outro e um pelo outro. Justamente neste lugar ocorre a coincidência do som e do sentido, naquilo que eles têm em comum, a remissão. O sentido é a remissão de um signo a alguma coisa, assim como o som não deixa de ser uma remissão: a propagação de ondas sonoras no espaço. Contudo, recuperando ideia de aesthesis de Aristóteles, diz Nancy que este é um sentir reflexivo. Soar é vibrar em si mesmo, portanto, é ressoar-se. Se estar à escuta é sempre um acesso a si mesmo, Nancy sugere então que esta seria uma oportunidade de se colocar em crisis. Estar à escuta é uma crise de si. Essa ressonância de uma remissão é como ouvir o vazio, ou, para usar o termo da alegoria do filósofo francês, ouvir o próprio silêncio (do sentido).

De fato, o lugar para o qual Nancy aponta, ao se posicionar à escuta, é o corpo, este é

\footnotetext{
${ }^{5}$ A pura ressonância - materialidade sonora, vibração, é importante que se diga, assim como frisa Nancy muitas vezes, não está ausente em outros regimes sensíveis. Assim como acontece com a sonoridade, poderia se pensar na cor ou na textura.
} 
o lugar da ressonância, condição de abertura do sentido para além da significação, o "pas au délà”, neste caso, o próprio sujeito é entendido como aquilo que, no corpo, está ou vibra à escuta do ultrassentido. Escrever, portanto, expor-se, desde Benjamin, Blanchot, Barthes ou Derrida, assim como em Nancy ou Agamben e também João Cabral, é fazer ressoar além da mera significação e também além de si mesmo.

O som ou a voz, em torno da qual se está ficcionalizando, também significa ditar, dar o tom, assim sendo, a opção de João Cabral nesse aspecto é bastante interessante. O poeta brasileiro que elege a morte como mote insiste reiteradamente em reivindicar a tradição trovadoresca na sua poesia. A eleição das formas fixas, mais precisamente a obsessão pelo aspecto formal que alude à tradição trovadoresca, associada aos fantasmas nordestinos e sevilhanos, tudo isso não pode ser negligenciado. As quadrinhas - o livro Quaderna é todo composto por quadras, por exemplo - e mesmo os dísticos escritos em redondilhas que aparecem em grande parte da obra de João Cabral são a reivindicação ou o chamado dessa tradição. Valeria lembrar que esse apelo a certa cultura se dá não pela tópica, mas pela forma - no arranjo e escolha das palavras - o que remete automaticamente ao som, e, consequentemente, reverbera no sentido. Tratar do som, trazer pelo som ecos de outros tempos, é trazer à baila um fantasma que apela à voz em vez da linguagem.

Antes de pensar esses espectros da cultura ibérica que aparecem na poesia de João Cabral, é relevante mencionar que Luiz Costa Lima, em seu estudo sobre a obra de João $\mathrm{Cabral}^{6}$, vai apontando livro a livro os procedimentos formais do poeta pernambucano. Em Pedra do sono, ele reserva as formas surrealistas a Murilo Mendes e os versos parentéticos ou a autonomia formal das estrofes e, até mesmo, os poemas de ironia cotidiana, à influência drummondiana. Por fim, fazendo alusão à epígrafe, diz que o procedimento cabralino trata-se de uma subversão mallarmaica. Sobre o segundo livro, diz Costa Lima: "a segunda obra do poeta, Os três mal-amados (1943), é tão esguia que hesito em chamá-la de livro. Despretensiosa, não passa de um único comentário em prosa do Quadrilha de Drummond. A influência deste não tem nenhum disfarce". (Lima, 1968, p.250). O ponto que gostaria de trazer à baila trata da verificação de Costa Lima, ao afirmar que a partir de $O$ engenheiro o poeta "começa a fundar sua singularidade à medida que consegue formalmente precisar uma resposta à problematicidade atual da poesia". (Lima, 1968, p.259). É pelo cuidado formal que Costa Lima caracteriza a peculiaridade cabralina. Reivindicado pelos concretos, o poeta construtor é entendido sempre como um calculista que mede com precisão obsessiva a sua construção.

'LIMA, Luiz Costa. Lira e antilira. Rio de Janeiro: Editora Civilização Brasileira, 1968. 
João Cabral de Melo Neto era calculista, não resta dúvida de que esta também é uma característica da sua obra, no entanto, se concordarmos com essa afirmação de Costa Lima, não podemos aceitar, por outro lado, que os primeiros livros eram menos importantes ou menos poéticos. Nos primeiros livros, a morte ainda não tinha a saliência cortante que irrompe no resto de sua obra. A morte, entenda-se, é um lugar de jogo. E esse jogo da linguagem de maneira alguma pode ser desvinculado do aspecto formal.

A cultura da Península Ibérica medieval misturada à cultura sevilhana e nordestina é uma abordagem anacrônica por excelência, que nos aponta um Brasil arábico, uma Sevilha brasileira, enfim, um pathos irrepresentável da cultura. Para pensar essa questão, poder-se-ia recorrer ao estudo da poesia trovadoresca feito por Segismundo Spina. Para Spina e os estudiosos por ele consultados, na Idade Média, a poesia feita na Península Ibérica era demasiadamente intelectualizada, isto é, circunscrita a um formalismo consagrado, feita a partir de algumas tópicas. Essas tópicas estabelecidas de acordo com a prática cavalheiresca e a moral católica estão imersas num discurso que retoma em grande medida as ideias platônicas. Essa retomada se dá, segundo Spina, pela poética andaluzo-arábica, fonte da poesia provençal e também galego-portuguesa. Isso porque os poetas arábicos foram os primeiros tradutores da filosofia platônica e logo incorporaram aquelas ideias à sua poesia. Além disso, o próprio catolicismo e os ideais de nação que começavam a brotar naquele período indiretamente traziam os ideais platônicos que, em poesia, traduzia-se no amor cortês, na obediência e serviço amoroso, na superioridade da mulher, no sofrimento agradável, entre outros. Pois bem, para Spina, a poesia medieval, grosso modo, era uma prática em que o trovador, aparentemente distanciado da realidade, punha-se a cantar topos, logo, punha-se a conformar as palavras a partir de certos lugares fixos.

$\mathrm{Na}$ concepção de Agamben sobre esse mesmo assunto, aquilo que caracteriza a poesia trovadoresca é uma outra interpretação da tópica da retórica antiga. Se anteriormente a tópica era o lugar de onde surge o discurso, onde acessar a busca pelos argumentos do discurso, a poesia europeia moderna, mais precisamente a poesia trovadoresca, por volta do século XII, deixa de utilizar os topoi como lugares da linguagem mais ou menos fixos, a partir do qual os oradores argumentavam o seu discurso. A ratio inveniendi - razão ou método de descobrir - torna-se a raz̧o de trobar, de onde provém o nome trobador. Segundo Agamben, trobar, etimologicamente, vem do latim vulgar tropare, que mais tarde se transforma em tropus - figura retórica, ou, na acepção musical, um canto inserido na liturgia. O mais relevante, no entanto, é que o trobar (em italiano moderno encontrar), para Agamben, indica a experiência da palavra própria do canto e da poesia. 
Pensando em Santo Agostinho, mais propriamente na mudança radical da experiência da linguagem que o advento do cristianismo causou, o filósofo italiano afirma que a inventio se torna o desejo amoroso do qual a palavra nasce:

\begin{abstract}
Com os poetas provençais, a superação da tópica clássica está, a esta altura, definitivamente concluída. O que eles experimentam como trobar remete decisivamente para além da inventio: os trovadores não querem rememorar argumentos já entregues a um topos, e sim ter experiência do topos de todos os topoi, ou seja, do próprio ter-lugar na linguagem com argumento originário, do qual exclusivamente podem fluir os argumentos no sentido da retórica clássica. O topos não pode mais, por este motivo, ser um lugar de memória no sentido mnemotécnico, mas, na trilha do appetitus agostiniano, ele se apresenta agora como um lugar de amor. Amors é o nome que os trovadores dão à experiência do advento da palavra poética, e amor é, portanto, para eles, a raz̧o de trobar por excelência. (Agamben, 2006, p.92)
\end{abstract}

É certo que amor trovadoresco não se trata de um amor biográfico ou psicológico, mas também não se trata, como acredita Spina, de um mero topos da linguagem. $\mathrm{O}$ amor, assim como assume Agamben, é um viver a linguagem como experiência amorosa e poética, toda e qualquer anedota bibliográfica é inventanda, ou antes trovato - encontrada. Nesse caso, é possível pensar que a sobrevivência da lírica trovadoresca no que tange à forma, em João Cabral, é uma busca própria de uma experiência única da ou com a linguagem. Afinal, o ter-lugar na linguagem como amor implica uma negatividade fundamental, já que a experiência do nada, como nos direciona Agamben, é o inencontrável - o amor inatingível nos poetas provençais é a própria experiência do nada. No caso de João Cabral, não se trata de um amor inatingível, mas antes o próprio ato sexual, a morte. É importante lembrar que Leiris, ao pensar a tauromaquia, não hesitou em aproximá-la da arte ou do amor erótico. Desde os trajes don-juanescos do matador, sua atuação coreográfica à figura fálica do touro, no vaievem dos passes e ritmos que se encerra com uma penetração. A tauromaquia, deve-se mencionar, ao presumir a morte, também encerra uma experiência de amor, principalmente no caso da aniquilação de ambos, como no caso de Manolete, porque só na morte há a comunhão total entre dois seres.

A experiência da morte ou da linguagem se dá na língua. No caso da língua portuguesa, pela sonoridade desta. Diferentemente dos trovadores provençais, que davam lugar aos versos de dez sílabas poéticas, na Península Ibérica, o privilégio, entre outros, era dado aos versos com sete sílabas poéticas, a redondilha maior. O uso da redondilha maior é uma constante em João Cabral. E esse fato remete, além do formalismo estético da poesia galaico-portuguesa, à cultura oral do nordeste. Remete acima de tudo à infância. João Cabral, em entrevista apresentada no curta-metragem Quatro vezes quatro disse que, na adolescência, odiava literatura, porque a ele a literatura era apresentada como o soneto em decassílabos, aquilo que o poeta chamava de "ritmo rançoso", isso porque embalava, fluía. 
Por isso, o poeta nos seus poemas fazia questão de não embalar o leitor, de usar a palavra como pedra no meio do caminho, por meio de uma poesia que é difícil de ler em voz alta, uma poesia "áspera", que exige esforço e riscos. A infância no Recife, as fazendas e os engenhos de cana-de-açúcar da família, a amizade com Carlos Drummond de Andrade e Manuel Bandeira, os cargos que assumiu depois de ter sido nomeado para o Itamatary, em 1945, o que o fez morar em diversos países, incluindo aquele que mais o marcou, a Espanha, são fatores que levaram, junto com a paixão pela literatura, o poeta a uma compreensão muito estética da linguagem. O folclore catalão, o folclore peninsular ibérico medieval, a cultura nordestina contemporânea, a cultura sevilhana contemporânea, tudo se mistura para formar uma pedra cheia de fissuras do tempo, a poesia.

A Espanha, de modo especial, de acordo com o ex-assessor de João Cabral, Durval Carvalho de Barros ${ }^{7}$, de todos os países que o diplomata pernambucano morou, foi aquele que mais o atravessou. Para o leitor de sua poesia, não há nenhuma novidade nessa informação, uma vez que as paisagens e a expressão cultural estão ali sempre presentes. Frequentador dos bares que os toureiros iam beber após as touradas e das apresentações de canto e dança flamencas, João Cabral sentia aquela cultura. Sentia ali algo que se correspondia com o nordeste: o elemento trágico.

A correspondência entre as imagens nordestinas e espanholas é algo que conserva traços árabes, ibéricos, mas que, sobretudo, explode o que é o Árabe, o Ibérico, o Brasil. A equivalência de Recife e Sevilha implica uma concepção de cultura em que o tempo linear é abolido. A concomitância de elementos de tempos e lugares distintos na poesia, ou melhor, numa poesia cuidadosamente ritmada, portanto, libera da sua simples estância, para, com o ritmo, tornar-se escansão e cadência desunindo a sucessão linear. Essa prega no tempo, por outro lado, traz uma dimensão corporal, porque musical, àquela poesia. A poesia João Cabral ressoa. E essa ressonância de restos é muito mais que um procedimento, é uma exigência. $\mathrm{O}$ agenciamento da morte sempre pulsante, como no título do poema que dá nome ao livro Crime na Calle Relator, ou como num outro poema do livro chamado de "O ferrageiro de Carmona”, é uma posição, sobretudo política, é escolha do ferro forjado em detrimento do ferro fundido:

\footnotetext{
Um ferrageiro de Carmona, que me informava de um balcão: "Aquilo? É de ferro fundido, foi a forma que fez, não a mão. Só trabalho em ferro forjado que é quando se trabalha ferro
}

\footnotetext{
${ }^{7} \mathrm{~A}$ menção se dá numa das entrevistas que compõe o curta-metragem Quatro vezes quatro.
} 
então, corpo a corpo com ele, domo-o, dobro-o, até o onde quero.

O ferro fundido é sem luta

é só derramá-lo na forma.

Não há nele a queda de braço

e o cara a cara de uma forja.

Existe a grande diferença

do ferro forjado ao fundido:

é uma distância tão enorme

que não pode medir-se a gritos.

$[\cdots]$

Forjar: domar o ferro à força,

Não até uma flor já sabida,

Mas ao que pode até ser flor

Se flor parece a quem o diga.

(Melo Neto, 1994, p.595-596)

Essa flor-poema, não pré-sabida, nem pré-constituída, é uma flor sempre em movimento, que justamente coloca em movimento os tempos. Longe de ser uma flor ideal, é fruto de um trabalho forçado, de uma luta (uma luta com as palavras, diria Drummond), e, como toda flor, é efêmera, está destinada à morte:

\footnotetext{
Poesia, te escrevia:

flor! conhecendo

que és fezes. Fezes

como qualquer,

gerando cogumelos

(raros, frágeis cogu-

melos) no úmido

calor de nossa boca.
}

(Melo Neto, 1994, p.98)

A poesia, em João Cabral, é a morte. É essa exposição de si mesmo, do próprio corpo ao monstro, seja ele o touro ou a seca. É a morte enquanto lugar da linguagem, de onde o sujeito emerge, é a morte/vida, morte enquanto declínio, que é sempre passagem para o vir-a-ser. Um delírio (de pânico) que conserva a lira, subvertendo-a.

\section{Referências bibliográficas}

AGAMBEN, Giorgio. A linguagem e a morte: um seminário sobre o lugar da negatividade. Belo Horizonte: Editora UFMG, 2006.

BENJAMIN, Walter. Charles Baudelaire um lírico no ange no capitalismo. Trad. José Martins Barbosa, Hemerson Alves Baptista. 1. ed - São Paulo: Brasiliense, 1989. 
LEIRIS, Michel. Espelho da tauromaquia. São Paulo: Cosac Naify Edições, 2001.

LEMINSKI, Paulo. Ensaios e anseios crípticos. Curitiba: Pólo editorial do Paraná, 1997.

LIMA, Luiz Costa. Lira e antilira. Rio de Janeiro: Editora Civilização Brasileira,1968.

LINK, Daniel. Fantasmas: Imaginación y sociedad .-1 ed. - Buenos Aires: Eterna Cadencia Editora, 2009.

MELO NETO, João Cabral de. Correspondência de Cabral com Bandeira e Drummond (Flora Süssekind, org.). Rio de Janeiro: Nova Fronteira, Fundação Casa de Rui Barbosa, 2001.

MELO NETO, João Cabral de. Obra completa. Organização Marly de Oliveira. Rio de Janeiro: Nova Aguilar, 1994.

NANCY, Jean-Luc. A la escucha. - 1 ed. Buenos Aires: Amorrortu, 2007.

SPINA, Segismundo. Do formalismo estético trovadoresco. 2 ed. São Paulo: Ateliê Editorial, 2009. 